ROCZNIKI TEOLOGICZNE

Tom LXVI, zeszyt 8 -2019, s. 125-138

DOI: http://dx.doi.org/10.18290/rt.2019.66.8-9

TEODOR PUSZCZ SChr

\title{
LITURGISCHE TEXTE ZU EHREN DER HEILIGEN DREI KÖNIGE
}

\section{LITURGICAL TEXTS IN HONOR OF THE SAINT THREE KINGS}

Abstract. This article is about showing the reader a very small passage of a much broader topic: Liturgy for travelers, pilgrims and sailing on the sea. Based on the research, it turned out that the Church, as evidenced by the first written liturgical sources, i.e. the sacramentaries and then especially, at the height of the Middle Ages, the pontificals, the missals and the rituals, took care of these people by preparing appropriate liturgical texts. Mass forms should be listed here: Pro iter agentibus, Pro peregrinantibus and Pro navigantibus. This is the first group. The second group is the rite of blessing of people going on a trip or on pilgrimage (Ordo ad servicium peregrinorum faciendum) or their travel equipment, such as a bag, a walking stick, a cross and a cloak (Benedictio ad baculum et ad peram) and the rituals of returning from pilgrimage or travel (Benedictio peregrinorum post reditum). In the post-Conciliar liturgy, few formulas of this wealth of prayers remain in use.

A separate and very interesting chapter are liturgical texts that are associated with the patronage of some saints, such as Saint James the Elder, Saint Raphael Archangel, Saint Julian, Saint Christopher, and Saint Three Kings. In the case of the Saint Three Kings, who were considered in the Middle Ages as patrons of travelers and pilgrims, and whose relics in the Cologne Cathedral attracted both newly crowned kings and crowds of other pilgrims from all over Europe, they were considered the first pilgrims of the Christian age who made pilgrimage to the newborn Jesus Christ. It is puzzling that the Mass forms (because the rites of blessing are unknown) can be classified into four distinct groups. Across Europe - from England to Germany and Poland they can be found in many medieval missals, but not in Cologne missals.

This article presents only the first Mass form De tribus magis pro iter agentibus. Mass orations develop the theme of the mags' path from the East to Bethlehem to bow to the Messiah, whose special star came up in the sky and led them to Him, so that they could celebrate Him with mystical gifts. The Church prays for own faithful on their pilgrimage that through these saints and through their merits the pilgrims would abound in peace, health and prosperity. May Christ Himself, called the true Sun, Star and Light, lead them unscathed to the desired sanctuary. Further, the Church asks God to send pilgrims an Angel of Peace as a companion on the road, guarding them against the dangers of the body and soul and against the attacks of the old enemy, i.e. Satan, and that they become worthy of the Holy Spirit's company. Another thought raised in euchology is the history of the Son of God (incarnation, passion and resurrection) and the role of

Dr TEODOR Puszcz SChr - Ratsherr der Provinz vom hl. Joseph (Deutschland, Italien, Niederlande, Ungarn) der Societatis Christi, Pfarrer in Bochum; Korrespondenzadresse: Stühmeyerstr. 45a, 44787 Bochum; E-Mail: ks.teodor@pmk-bochum.de 
angels as his witnesses, which is to express in the care of pilgrims day and night. The first Bible reading (Gen 24:7) is about Abraham's journey to his homeland and the promise of an Angel as a companion on the road. On the other hand, the Gospel pericope (Lk 4:23b-30) is a conversation between the Pharisees and Jesus, who is not welcomed in his homeland. During this conversation, the tension between the homeland and the exile, between the stranger and the own plays an important role. For this reason, the pericope was probably chosen for the Mass form. Mass antiphons (introitus, graduale, offertorium and communio) have fragments of Psalms as their source and take up typical motifs for the discussed subject: God leading on the road, the company of angels on the road, trust in God and rescue in God. The sequence Maiestati sacrosantae militans, which was sometimes attached to this form, will be discussed in a separate article.

Key words: travel; pilgrimage; liturgy for travelers, pilgrims and sailing on the sea; God's protection on the way; Saint Three Kings; saint patrons; angels.

Aus dem Hoch- und Spätmittelalter sind Messformulare und Gebetstexte für Pilger und Menschen unterwegs überliefert worden, die bei den liturgischen Feiern zu Ehren der Schutzpatrone der Pilger oder der Reisenden oder aber der Seefahrer benutzt wurden. Und so boten die liturgischen Bücher meistens Messtexte und andere Gebetstexte zu Ehren des hl. Apostels Jakobus des Älteren, der Heiligen Drei Könige, des hl. Erzengels Raphael und des hl. Julian Hospitator. Nicht immer waren die neuen Patronate mit einem Ort des Kultes verbunden. Nur wenige liturgische Texte sind bis auf die heutige Zeit überliefert worden.

In Köln, dem Rom des Nordens, errichteten Pilger ein Zentrum mittelalterlicher Frömmigkeit und Reliquienverehrung. Hier gab es eigene Prozessionswege, die sich ebenso an den Riten der großen Kirchenfeste orientierten wie an den vielen Heiligen, deren Reliquien in Köln aufbewahrt und verehrt wurden. Mitte des 12. Jhs. war der Hohe Dom Ausgangspunkt und Ziel vieler innerstädtischer Wallfahrten. Ein wichtiges Ereignis bringt diese Stadt am Rhein für immer in Verbindung mit besonderen Reliquien ${ }^{1}$. Im Jahre 1164 brachte der Erzbischof Reinald von Dassel die Gebeine der Heiligen Drei Könige als Kriegsbeute aus Mailand nach Köln, wo man ihnen einen

\footnotetext{
${ }^{1}$ Das Evangelium (Mt 2,1-12) berichtet über die Huldigung des Heilandes in Bethlehem durch drei Magier aus dem Morgenland. Tertullian (um 160 - nach 220) als erster bezeichnet sie als ,drei Könige“" (ab dem 6. Jh. ständiger Sprachgebrauch). Etwa ab dem 9. Jh. sind ihre Namen bekannt: Kaspar, Melchior und Balthasar und, dass einer der drei Männer von dunkler Hautfarbe war. Die angeblichen Reliquien der Drei Könige sollen von der Kaiserin Helena (248/9 - 328/9) nach Konstantinopel gebracht worden und von dort im 6. Jh. in die Kirche S. Eustorgius nach Mailand gelangt sein, die sich vor den Stadtmauern befand und ab dem 9. Jh. als Basilica Regum bezeichnet wurde. Bei der ersten Belagerung 1158 wurden die Reliquien in das Innere der Stadt gebracht. Nachdem Mailand im 12. Jh. zerstört worden war, soll Kaiser Friedrich Barbarossa die Reliquien seinem Kanzler Reinold von Dassel geschenkt haben. Vgl. dazu Vera SCHAUBER und Hanns Michael SCHINDLER (Hgg.), Bildlexikon der Heiligen, Seligen und Namenspatrone (Augsburg: Pattloch, 1999), 145-146.
} 
der größten Reliquienschreine des Mittelalters errichtete. Die deutschen Könige machten jeweils nach ihrer Krönung eine Wallfahrt nach Köln zum Dreikönigsschrein, einen der kostbarsten Reliquienschreine des Mittelalters. Bemerkenswert ist, dass trotz des Reichtums an Reliquien Köln für viele Pilger nicht Ziel, sondern Durchgangsort und Station auf dem Weg nach Aachen, Rom oder Santiago gewesen ist. ${ }^{2}$ Es ist anzunehmen, dass aus den Festen $^{3}$, Wallfahrten und Patrozinien der Kult ${ }^{4}$ der Heiligen Drei Könige entstand, die unter anderem als Schutzpatrone der Reisenden ${ }^{5}$ und Pilger verehrt wurden, so dass die Missalien des Mittelalters in ganz Europa, die Messtexte einer Missa de tribus magis pro iter agentibus verzeichnen. Bemerkenswert ist dabei, dass die Kölner Messbücher selbst dieses Messformular nicht kennen. ${ }^{6}$ Die Messformulare sind so unterschiedlich zusammengesetzt worden, dass sie in vier Gruppen aufgestellt werden mussten.

\section{MESSFORMULAR A}

Die Texte der Messe mit dem Titel: De tribus magis pro iter agentibus wurden in einem Evagatorium ${ }^{7}$ (kleinformatiges Messbuch für die Reise, das mehrere Votivmessen enthält) vorgeschlagen.

\footnotetext{
${ }^{2}$ Vgl. Karl-Heinz FlinsPaCh und Annette Heusch-Altenstein, Jakobswege. Wege der Jakobspilger im Rheinland, Bd. 1 (Köln: J.P. Bachem Verlag, 2001), 69.

${ }^{3}$ Für die Kölner Kirche sind neben dem Epiphaniefest (6. Januar) das Translationsfest am 23. Juli (zeitweilig am 24.) belegt sowie die einzeln kommemorierten Todestage der Heiligen (Kaspar 1.1.; Melchior - 6.1; Balthasar - 11.1.) und ein gemeinsames Fest am 12. Januar. Vgl. dazu E. Dassmann. Epiphanie und die Heiligen Drei Könige in: Die Heiligen Drei Könige - Darstellung und Verehrung. Katalog zur Ausstellung des Wallraf-Richartz-Museums in der Josef-HaubrichKunsthalle Köln (1. Dez. 1982 bis 30. Jan. 1983) (Köln, 1982), 16-19.

${ }^{4}$ Sechs Kirchen sind im Erzbistum Köln den Heiligen Drei Königen geweiht: Bergisch Gladbach (Hebborn), Köln (Bickendorf), Köln (Rondorf), Leverkusen (Bergisch Neukirchen), Neuss, Wachtberg (Oberbachem). Vgl. dazu Personalschematismus für das Erzbistum Köln 1997/98. Köln 1997, 579-612. In Rom gibt es eine einzige Heilige Drei Könige - Kapelle, die sich innerhalb des Palazzo di Propaganda Fide (Piazza di Spagna 46) befindet.

${ }^{5}$ Die früheren Darstellungen der Magier aus dem Morgenland zeigen sie konsequent im kurzen Gewand, wie das auch in den späteren Abbildungen der Pilger oder Reisenden der Fall ist.

${ }^{6}$ Jakob Torsy erwähnt, was die liturgische Feier der Heiligen Drei Könige im Dom zu Köln angeht, zwei Termine im liturgischen Kalender des Erzbistums (Fest der Epiphanie - 6. Januar und Gedächtnis der Übertragung der Gebeine - 23. Juli). Außerdem nennt er ein Votivoffizium und eine Votivmesse De tribus Regibus, die die alte kölnische Liturgie kannte. Die Texte stimmten mit den Texten des Translationsfestes überein und konnten an Dienstagen genommen werden, aber nicht in den verbotenen Zeiten. Dazu vgl. Jakob ToRSY, Achthundert Jahre Verehrung der Heiligen Drei Könige in Köln 1164-1964 (= Kölner Domblatt 23/24) (Köln: J.P. Bachem Verlag, 1964), 35-44.

${ }^{7}$ Missale itinerantium, Coloniae 1499, München BSB, Sign. $8^{\circ}$ Inc. c. a. 324 (Weale-Bohatta, Nr. 459), fol. g3r-g4r; vgl. dazu Adolph FranZ, Die Messe im deutschen Mittelalter (Freiburg:
} 
Das Messformular für Reisende zur Ehre der Heiligen Drei Könige wurde folgendermaßen zusammengestellt:

Introitus A: Esto mihi [Ps 30, 3-4]. V. In te Domine speravi [Ps 30, 2]. Gloria Patri. Esto mihi.

Oratio A: Deus, qui tres magos orientales, Jaspar Melchior et Balthasar ad Filii tui Domini nostri Iesu Christi cunabula.

Lectio A: Lectio libri Genesis. XV [Gn 24, 7].

In diebus illis locutus es abraham dicens. Dne deus celi et terre misit me de domo patris mei... angelum suum qui praecedat nos dirigens gressus nostros in viam pacis.

Graduale A: Angelis suis mandavit de te [Ps 90, 11]. V. In manibus portabunt te [Ps 90, 12].

Alleluia A: Alleluia. V. Ostende nobis Domine [Ps 84, 8]. Alleluia.

[Sequentia A: Maiestati sacrosanctae militans].

Evangelium A: Secundum Lucam IIII. cap. [Lc 4, 23b-30].

In illo tempore. Dixerunt pharisei ad ihesum. Quanta adiuuimus facta in capharnaum... Ipse autem transiens per medium illorum ibat.

Offertorium A: Perfice gressus meos in semitis tuis, ut non moveantur vestigia mea: inclina aurem tuam, et exaudi verba mea: mirifica misericordias tuas, qui salvos facis sperantes in te, Domine [Ps 16, 5-7].

Secreta $A$ : Deus qui es gloria sanctorum et diriges viam iustorum $(\approx$ Sacramentarium Sangallense 189; weiter $\mathrm{Ch}$ ).

Communio A: Tu mandasti mandata tua custodire nimis: utinam dirigantur viae meae, ad custodiendas iustificationes tuas [Ps 118, 4-5]

Complenda A: Omnipotens sempiterne Deus, qui misisti Filium tuum.

Das Messformular besteht aus den Vorstehergebeten (Oratio, Secreta, Complenda), zwei biblischen Lesungen und Messgesängen. Es ist bemerkenswert, dass eine entsprechende Präfation nicht vorgeschlagen wurde.

Die Messantiphonen (Introitus, Graduale, Offertorium, Communio) wurden oft aus den Messformularen Pro iter agentibus aus den Sakramentaren und Messbüchern übernommen.

Die erste Lesung, die hier angeboten wurde, gehört zum Standard der Messe für Reisende und findet sich oft schon in den Sakramentaren und Vollmissalien. Das Evangelium dagegen stellt eine Perikope aus dem Lukasevangelium dar, das erstmalig hier vorgeschlagen wurde.

Die Sequenz Maiestati sacrosanctae militans, die eigentlich dem Messformular des Festes In Epiphania Domini angehört, wurde in einigen Quellen den vorliegenden Messtexten beigefügt. Sie wird bei der Besprechung des Messformulars B untersucht.

Herder, 1902), 216; auch das Missale itinerantium, Coloniae 1503, München BSB, Sign. Res/Hom. 447i (Weale-Bohatta, Nr. 465), fol. C-IIIr-C-IIIv verzeichnet die gleiche Messe; im Missale itinerantium, Coloniae 1503, Trier SB, Sign. F $32 \mathrm{~m} 8^{\circ}$ fol. G 3-4 ist am Anfang dieses Messformular zu finden; sowie im Missale itinerantium, 1503, München BSB, Sign. Res/ Liturg. 823, fol. C-IIIr-C-IIIv. 
Das zuerst vorgesehene von dem Vorsteher der Liturgie zu sprechende Tagesgebet verdient eine genauere Untersuchung:

Oratio $A$

Deus qui tres magos orientales Jaspar Melchior et Balthasar ad filii tui domini nostri iesu xpi cunabula vt cum misticis adorarent muneribus sine impedimento duxisti et reduxisti. concede famulis tuis: vt in hoc itinere quo peracturi sunt: per ipsorum trium regum pias intercessiones et merita pacem et prosperitatem ac sanitatem quatenus ipso vero sole vera stella et vero lumine ducente ad loca optata sine offensione et impedimento peruenire mereantur. Per eundem. ${ }^{8}$

Die erste Oration besitzt eine fast klassische Orationsstruktur - die Prädikation fehlt. Das Gebet wechselt am Ende der Precatio das Subjekt. Auf einmal ist von Christus die Rede.

Der Gebetstext ${ }^{9}$ fängt mit der Anaklese und Anamnese an: Gott, du hast die drei Magier Kaspar, Melchior und Balthasar (Deus, qui tres magos orientales, Caspar, Melchior et Balthasar ${ }^{10}$ ) ohne Aufenthalt aus dem Orient zur Wiege unseres Herrn Jesus Christus geführt und wieder zurück in ihre Heimat (ad filii tui Domini nostri Iesu Christi cunabula, ut eum mysticis adorarent muneribus ${ }^{11}$, sine impedimento duxisti et reduxisti ${ }^{12}$ ), damit sie ihn mit ihren mystischen Gaben verehren konnten. Das biblische Motiv der Reise der Magier nach Betlehem wird erkennbar.

Weiter folgt eine Precatio. Es wird darum gebetet, dass Gott seinen Dienern auf dieser Pilgerreise, die sie antreten wollen (Concede famulis tuis, ut in hoc itinere, quo peracturi sunt ${ }^{13}$ ), auf die huldvolle Fürsprache und durch die Verdienste eben dieser drei Könige (per ipsorum trium regum pias intercessiones ${ }^{14}$ et merita) Frieden, Wohlergehen und Gesundheit gewähren

\footnotetext{
${ }^{8}$ Gott, du hast die drei Magier Kaspar, Melchior und Balthasar ohne Aufenthalt aus dem Orient zur Krippe unseres Herrn Jesus Christus geführt und wieder zurück in ihre Heimat, damit sie ihn mit ihren mystischen Gaben verehren konnten. Gewähre deinen Dienern auf dieser Pilgerreise, die sie antreten wollen, auf die huldvolle Fürsprache und durch die Verdienste eben dieser drei Könige Frieden, Wohlergehen und Gesundheit. Lass sie von dir, der wahren Sonne, dem wahren Stern und dem wahren Licht, geführt ohne Ärgernis und Hindernis zu den ersehnten Pilgerstätten gelangen.

${ }^{9}$ Corpus orationum 160B, 3, Nr. 2133a. Weitere Quellen: Missale Aquileyensis Ecclesiae 300v (weiter Aquilea).

${ }^{10}$ Vgl. Durandus-Pontifikale 10, 3 (weiter PRD); im Matthäusevangelium wird berichtet: Cum autem natus esset Iesus in Bethlehem Iudaeae in diebus Herodis regis, ecce Magi ab oriente venerunt Hierosolymam (Mt 2, 1).

${ }^{11}$ Mt 2,11: Et intrantes domum viderunt puerum cum Maria matre eius, et procidentes adoraverunt eum; et apertis thesauris suis, obtulerunt ei munera, aurum et tus et myrrham.

${ }^{12} \mathrm{Vgl}$. Mt 2,12.

${ }^{13}$ Vgl. Gelasianum Vetus 1319 (weiter GeV) = Supplementum Anianense 1319 (weiter Sp).

${ }^{14}$ Vgl. Sp 1726; Liber Ordinum sacerdotalis z Silos 422 (weiter $\mathrm{S}^{3}$ ).
} 
möge $\left(\right.$ pacem $^{15}$ et prosperitatem ${ }^{16}$ ac sanitatem $\left.^{17}\right)$. Sie sollen von Christus, der wahren Sonne, dem wahren Stern und dem wahren Licht, geführt (quatenus, ipso vero sole, vera stella ${ }^{18}$, vero lumine ${ }^{19}$ ducente, ad loca $^{20}$ optata) ohne Ärgernis und Hindernis zu den ersehnten Pilgerstätten gelangen (sine offensione ${ }^{21}$ et impedimento pervenire mereantur).

Die nach der Gabenbereitung angebotene Secreta wird nach den Einzelheiten befragt:

Secreta A

Deus qui es gloria sanctorum et diriges viam iustorum: dirige angelum pacis cum famulis tuis qui eos ad locum quo pergunt cum iocunditate prosperitate et pace sine impedimento anime et corporis ducant et reducant eisque non possint nocere antiqui hostis insultus. Procul sit ab eis omnium malorum accessus. et comes eorum dignetur esse spiritus sanctus. Per dominum nostrum. ${ }^{22}$

Das Gabengebet weist eine unvollständige Secreta-Struktur auf. Es fehlt die Precatio I - Annahmebitte der Gaben. Der Anfang der Oration und der Abschluss weisen Ähnlichkeiten mit der entsprechenden Oration (Ch 189) des Sangallense auf. Es ist möglich, dass der Verfasser diese Oratio (ohne exakte liturgische Bestimmung) vor Augen hatte als er diese Secreta kompilierte.

Die nach der Gabenbereitung zu sprechende Oration ${ }^{23}$ fängt ebenso mit der Anaklese und einer Prädikation an: Gott, du bist der Ruhm der Heiligen und lenkst den Weg der Gerechten (Deus, qui es gloria sanctorum et dirigis viam iustorum ${ }^{24}$ ).

\footnotetext{
${ }^{15}$ Vgl. Pontificale Curiae Romanae 20, 4 (weiter PCR); Liber Pontificalis Rotae 67, 11 (weiter PRod).

${ }^{16}$ Vgl. Sp 1726; Sacramentarium Gregorianum 2744 (weiter Gr); Sacramentarium Gellonense 2802 (weiter G); PCR 20, 4; PRD 30, 1; Magdalen Pontificale 1, 1 (weiter MP); PRod 68B, 8; PRod $68 \mathrm{~B}, 11$

${ }^{17}$ Vgl. Liber Ordinum episcopalis z Silos 164 (weiter $S^{4}$ ).

${ }^{18}$ Im Buch Numeri sind die Worte des Balaam zu lesen: Orietur stella ex Iacob, et consurgit virga de Israel; et percutit tempora Moab et verticem omnium filiorum Seth (Nm 24, 17b). Im letzten Kapitel der Offenbarung des Johannes sagt Jesus: Ego sum radix et genus David, stella splendida matutina (Apc 22, 16b).

${ }^{19}$ Io 1, 9: Erat lux vera, quae illuminat omnem hominem, veniens in mundum.

${ }^{20}$ Vgl. GeV 1317; Ch 189; Ch 199; PCR 20, 4.

${ }^{21}$ Vgl. GeV 1314; Sacramentarium Engolismense 1854 (weiter A).

${ }^{22}$ Gott, du bist der Ruhm der Heiligen und lenkst den Weg der Gerechten. Gib deinen Dienern den Engel des Friedens mit auf den Weg, der sie in Freude, Wohlergehen und Frieden ohne Gefahr für Leib und Seele zu ihrem Bestimmungsort hin - und zurückführt, damit die Anfechtungen des Alten Feindes nicht schaden können. Halte fern von ihnen jeglichen Anschlag des Bösen und mache sie würdig der Begleitung des Heiligen Geistes.

${ }^{23}$ Corpus orationum, 160A, 2, Nr. 1586b. Weitere Quellen: Aquilea 301r.

${ }^{24}$ Vgl. Ch 189.
} 
Weiterhin wird in der Precatio darum gebetet, dass Gott seinen Dienern den Engel des Friedens mit auf den Weg geben möge (dirige angelum pacis ${ }^{25}$ cum famulis tuis ${ }^{26}$ ), der sie in Freude, Wohlergehen und Frieden ohne Gefahr für Leib und Seele zu ihrem Bestimmungsort hin- und zurückführe (qui eos ad locum $^{27}$, quo pergunt ${ }^{28}$, cum iucunditate, prosperitate ${ }^{29}$ et pace ${ }^{30}$, sine impedimento $^{31}$ animae et corporis ${ }^{32}$ ducat et reducat), damit ihnen die Anfechtungen des alten Feindes nicht schaden können (eisque non possint nocere antiqui hostis ${ }^{33}$ insultus). Er halte von ihnen jeglichen Anschlag des Bösen fern (procul sit ab eis omnium malorum accessus ${ }^{34}$ ) und mache sie würdig der Begleitung des Heiligen Geistes (et comes eorum dignetur esse Spiritus Sanctus $^{35}$ ). Das biblische Motiv der Begleitung durch einen Engel wurde in den Text eingebaut.

Dem für den Vorsteher der Liturgie reservierten Schlussgebet steht ebenso eine genaue Untersuchung zu:

Complenda $A$

Omnipotens sempiterne deus qui misisti filium tuum dominum nostrum iesum xpm de sinu tuo in vterum marie virginis vt homo fieret. et homo factus est: passus et sepultus. et misisti sanctos angelos tuos non vt custodirent: sed vt testimonium perhiberent vere resurrectionis. Te deprecamur piissime deus pro illorum trium regum orientalium interuentum. vt digneris angelos tuos mittere vt sint circa famulos tuos die ac nocte. vt sint securi in corpore et anima ac rebus omnibus in christo iesu domino nostro. Qui tecum viuit et cum. ${ }^{36}$

Die Complenda verrät eine unvollständige Struktur - es fehlt die Reflexion auf den Kommunionempfang.

\footnotetext{
${ }^{25} \mathrm{Vgl} . \mathrm{GeV} 1317=$ Gr 2738.

${ }^{26}$ Vgl. Ch 189.

${ }^{27}$ Vgl. GeV 1317 = Gr 2738; Ch 189; Ch 199.

${ }^{28}$ Vgl. PRD 10,3.

${ }^{29} \mathrm{Vgl}$. Oratio A.

${ }^{30} \mathrm{Vgl}$. ebenda.

${ }^{31}$ Vgl. ebenda.

${ }^{32}$ Vgl. PRD 30, 1; PRD 31, 2.

${ }^{33}$ Vgl. PCR 20, 6; PRD 30, 1; PRD 30, 2.

${ }^{34}$ Vgl. Ch 189.

${ }^{35} \mathrm{Vgl}$. ebenda.

${ }^{36}$ Allmächtiger, ewiger Gott, der du deinen Sohn, unseren Herrn Jesus Christus aus dem Schoße des Vaters in den Schoß der Jungfrau Maria gesandt hast, damit er Mensch werde. Er ist Mensch geworden, hat gelitten und ist begraben worden. Du hast deine heiligen Engel geschickt, nicht damit sie über ihn wachen, sondern damit sie Zeugnis geben von seiner wahren Auferstehung. Gott, auf die Fürsprache jener drei Könige aus dem Orient bitten wir dich inniglich, du wollest deine heiligen Engel senden, damit sie deine Diener Tag und Nacht beschützen. Dann werden sie an Leib und Seele und mit all ihrem Gut sicher sein in Jesus Christus unserem Herrn.
} 
Das nach der Kommunion zu sprechende Gebet ${ }^{37}$ setzt mit der Anaklese: Allmächtiger, ewiger Gott (Omnipotens sempiterne Deus) und einer langen Anamnese an: der du deinen Sohn, unseren Herrn Jesus Christus aus dem Schoße des Vaters in den Schoß der Jungfrau Maria gesandt hast (qui misisti Filium tuum Dominum nostrum Iesum Christum de sinu tuo $^{38}$ in uterum $^{39}$ Mariae virginis), damit er Mensch werde (ut homo fieret ${ }^{40}$ ). Er ist Mensch geworden, hat gelitten und ist begraben worden (et homo factus est, passus et sepultus ${ }^{41}$ ). Du hast deine heiligen Engel geschickt, nicht damit sie über ihn wachen (et misisti sanctos angelos tuos ${ }^{42}$, non ut custodirent), sondern damit sie Zeugnis geben von seiner wahren Auferstehung (sed ut testimonium $^{43}$ perhiberent verae resurrectionis). Im Text sind biblische Motive erkennbar: der Menschwerdung Christi und seines Leidens, Todes und Auferstehung sowie des Zeugnisses der Engel nach seiner Auferstehung.

Weiter wird in der Precatio darum gebetet, dass Gott auf die Fürsprache jener drei Könige aus dem Orient (te deprecamur, piissime Deus, per illorum trium regum orientalium interventum ${ }^{44}$ ) seine heiligen Engel senden möge, damit sie seine Diener Tag und Nacht beschützen (ut digneris angelos tuos mittere $^{45}$, ut sint circa famulos tuos die ac nocte). Dann werden sie an Leib und Seele und mit all ihrem Gut sicher sein in Jesus Christus unserem Herrn (ut sint securi in corpore et anima ${ }^{46}$ ac rebus omnibus in Christo Iesu

${ }^{37}$ Corpus orationum, 160E, 6, Nr. 3984. Weitere Quellen: Aquilea 301r.

${ }^{38}$ Io 1, 18: Deum nemo vidit umquam; unigenitus Deus, qui est in sinum Patris, ipse enarravit.

${ }^{39}$ Matthäus, nachdem er den Stammbaum Jesu aufgeführt hatte, beginnt mit der Beschreibung der Geburt wie folgt: Cum esset desponsata mater eius Maria Ioseph, antequam convenirent inventa est in utero habens de Spiritu Sancto (Mt 1,18b).

${ }^{40}$ Johannes Evangelist hat die berühmten Worte am Anfang seines Buchs geschrieben: Et Verbum caro factum est et habitavit in nobis; et vidimus gloriam eius, gloriam quasi Unigeniti a Patre, plenum gratiae et veritatis (Io 1,14).

${ }^{41}$ Vgl. Credo - das Apostolische Glaubensbekenntnis und das große Glaubensbekenntnis von Nizäa-Konstantinopel.

${ }^{42} \mathrm{Vgl}$. Mt 28,2: angelus enim Domini descendit de caelo; Mc 16,5: viderunt iuvenem sedentem in dextris; Lc 24, 4: ecce duo viri steterunt secus illas in veste fulgenti.

${ }^{43}$ Im Osterbericht des Matthäus sagte der Engel zu den Frauen: Nolite timere vos! Scio enim quod Iesum, qui crucifixus est, quaeritis. Non est hic: surrexit enim, sicut dixit. Venite, videte locum, ubi positus erat (Mt 28,5-6). Beim Markus spricht der junge Mann im weißen Gewand zu den Frauen in ähnlichen Worten (vgl. Mc 16,6). Dem Bericht des Lukas nach sprachen zwei Männer in leuchtenden Gewändern zu den Frauen: Quid quaeritis viventem cum mortuis? Non est hic, sed surrexit (Lc 24,5b-6a).

${ }^{44}$ Vgl. Oratio A.

${ }^{45}$ Vgl. Egbert Pontificale 1 (weiter EP); EP 2; Benedictionale Roberti Archiepiscopi 1 (weiter BR).

${ }^{46}$ Vgl. MP 1, 1; MP 2, 5; Pontificales z Cambridge 3, 2 (weiter PPCambr). 
Domino nostro). Das biblische Motiv der Begleitung durch einen Engel wurde hier eingeführt.

Auch der handschriftliche Anhang des Missale von Prag ${ }^{47}$ enthält auf fol. $12 \mathrm{v}-14 \mathrm{r}$ die gleiche Messe Pro tribus magis pro iter agentibus. Das Messformular besteht aus den gleichen Messgesängen, den gleichen biblischen Lesungen sowie fast gleichen Vorstehergebeten und enthält zusätzlich die Prosa (Maiestati sacrosanctae militans).

Die etwas abweichende Oratio wird ebenso nach den Einzelheiten befragt:

\section{Oratio A-1}

Deus qui tres magos orientales caspar melchior et balthasar ad filii tui domini nostri iesu xpi cunabula: vt cum misticis adorarent muneribus stella duce et vero lumine preuio sine impedimento duxisti et reduxisti: concede famulis tuis: vt in hoc itinere quo pereracturi sunt: et ipsorum trium regum pias intercessiones et merita pacem et prosperitatem ac sanitatem: quatenus ipso vero sole: vera stella et vero lumine ducente: ad loca optata sine offensione et impedimento peruenire mereantur. Per eundem. ${ }^{48}$

Der Verfasser dieser Oration hat die Version A mit dem Zusatz: stella duce et vero lumine praevio (nach dem Wort muneribus) ergänzt. Vielleicht hat er noch andere Vorlagen mit dem Formular B vor Augen gehabt. Dieses Gebet weist Ähnlichkeiten mit der Oratio PRD 10, 3 auf.

Ein Messbuch für die Reise ${ }^{49}$ bietet auf fol. 40v-42r auch die Messe De tribus Magis pro iter agentibus an. Das Messformular enthält grundsätzlich die Texte des Formulars A, mit Ausnahme der Oratio (A-1) und diesmal mit der Sequenz (Maiestati sacrosanctae militans).

Auch das Missale von Aquileia ${ }^{50}$ enthält auf fol. 300v-301r das gleiche Messformular mit dem Titel De tribus magis pro iter agentibus. Die Gebetstexte (Secreta, Complenda) entsprechen dem Formular A (Oratio A-1),

\footnotetext{
${ }^{47}$ Missale Pragense, Venetiis 1507, Prag NB, Sing. 46 A 52 (Weale-Bohatta, Nr. 801) vgl. dazu FranZ, Die Messe, 217.

${ }^{48}$ Gott, du hast die drei Weisen aus dem Orient Kaspar, Melchior und Balthasar zur Krippe unseres Herrn, Jesus Christus, unter der Führung eines Sternes, der ihnen als das wahre Licht den Weg wies, ohne Widerstand geführt, um ihn mit ihren geheimnisvollen Gaben zu verehren, und auch zurückgeleitet. Gewähre deinen Dienern, dass sie auf dieser Pilgerreise, die sie antreten wollen, durch die huldvolle Fürsprache und die Verdienste eben dieser drei Könige Frieden, Glück und Gesundheit. Lass sie unter deiner Führung, der du die wahre Sonne, der wahre Stern und das wahre Licht bist, ohne Ärgernis und Hindernis zu den ersehnten Wallfahrtstätten gelangen.

${ }^{49}$ Missale itinerantium, Oppenheim 1521, Trier SB, Sign. Inc. $15988^{\circ}$ (Weale-Bohatta, Nr. 476).

${ }^{50}$ Aquilea 1519.
} 
die biblischen Lesungen stimmen ebenso mit denen des Formular A überein. Die Messgesänge Introitus, Offertorium, Graduale, Offertorium und Communio sind mit den entsprechenden Gesängen des Formulars A identisch. Es wird hier auch die Sequenz Maiestati sacrosanctae militans angeboten.

\section{BIBLISCHE LESUNGEN}

Der sehr knappe Ausschnitt aus dem Buch Genesis $(24,7)$ wurde als erste Lesung immer wieder bei den Votivmessen für Reisende angeboten.

Diese Perikope wurde oft in den Messen De tribus magis pro iter agentibus vorgesehen ${ }^{51}$.

Im Fragment (V. 1-9) des 24. Kapitels des ersten Buches der Bibel wurde der Dialog Abrahams mit seinem Großknecht niedergeschrieben, in dem es sich um seine Reise in die Heimat Abrahams handelt. Er soll für Isaak eine Frau aus der Verwandtschaft auswählen, die er heiraten soll. Abraham bezog sich auf Gottes Güte in seinem Leben und machte dem Knecht eine Zusage: Gott wird seinen Engel vor dir hersenden, und so wirst du von dort eine Frau für meinen Sohn mitbringen. Die Begleitung durch einen Engel unterwegs ist ein Motiv, auf das häufig in den Texten der Messformulare zurückgegriffen wurde.

Als weitere Alternative wurde eine Perikope aus dem Lukas-Evangelium (4,23b-30) angeboten.

Das Fragment des Lukas-Evangeliums gibt das Gespräch Jesu mit den Pharisäern wieder. Jesus erfährt, dass er und seine Lehre in seiner Heimat nicht angenommen werden, daher sagt er das Sprichwort: Kein Prophet wird in seiner Heimat anerkannt. Im weiteren Verlauf des Gesprächs spielt die Spannung zwischen Fremde und Heimat und zwischen Fremden und Einheimischen eine Rolle. Gerade diese Erfahrung war den Menschen unterwegs nicht fremd. Aus diesem Grund ist die Wahl dieses Textes als Evangelium des vorliegenden Messformulars berechtigt.

\section{ANTIPHONEN DER MESSE}

Der Gesang, der die Eingangsprozession des Priesters zum Altar begleitete, Introitus genannt, wurde an dieser Stelle des Messformulars konsequent vorgeschrieben.

\footnotetext{
${ }^{51}$ Lectio des Messformulars A (De tribus magis). Mit Zusatz am Ende der Parikope: Domine Deus caeli et terrae misit me de domo patris mei...angelum suum, qui perducat nos dirigens gressus nostros in viam pacis; Lectio des Messformulars C (Missa pro viatoribus).
} 
Introitus $A$

Ant. Esto mihi in Deum protectorem, et in locum refugii, ut salvum me facias: quoniam firmamentum meum, et refugium meum es tu: et propter nomen tuum dux mihi eris, et enutries me [vgl. Ps 30,3b-4].

$P S$. In te Domine speravi, non confundar in aeternum: in iustitia tua libera me [et eripe me] [Ps 30,2]. Gloria Patri.

Ant. Esto mihi.

Der Antiphon liegen zwei Verse des Ps 30 zugrunde: Sei mir ein schützender Gott, ein Ort der Zuflucht, auf dass du mich errettest. Denn du bist meine Stärke und meine Zuflucht; um deines Namens willen wirst du mich führen und nähren. Der Psalmvers wurde dem gleichen Psalm entnommen und lautet: Auf dich hoffe ich, Herr. Lass mich doch niemals scheitern; rette mich in deiner Gerechtigkeit und befreie mich.

Als Zwischengesänge nach der ersten Lesung wurden vorgesehen Graduale und Versus Alleluiaticus. Gerade für die Osterzeit und für die anderen Zeiten (außer der Fastenzeit) wurde Versus alleluiaticus vorgesehen.

Der nachfolgende Gesang besteht aus dem Graduale und zwei Versus Alleluiatici. Eine Rubrik erklärt meistens, dass er an Stelle des Graduale tritt (Tempore autem paschali omittitur graduale, et eius loco dicitur).

Graduale und Versus A

[R.] Angelis suis [mandavit de te, ut custodiant te in omnibus viis tuis Ps 90,11].

$V$. In manibus portabunt [te, ne unquam offendas ad lapidem pedem tuum vgl. Ps 90,12].

Alleluia.

$V$. Ostende nobis, Domine, misericordiam tuam: et salutare tuum da nobis [Ps 84,8$]$ oder

Alleluia.

$V$. De profundis [clamavi ad te, Domine: Domine exaudi vocem meam Ps 129,1-2a].

Dem Zwischengesang liegen zwei Verse aus Ps 90 zugrunde, die jedoch etwas umgestaltet wurden: Er hat seinen Engeln befohlen, dich zu behüten auf all deinen Wegen. Der Vers lautet: Sie werden dich auf ihren Händen tragen, damit dein Fuß nicht an einen Stein stößt.

Die vorgeschlagenen Alleluia-Verse wurden unverändert den Psalmen 84 und 129 entnommen. Im ersten Alleluia-Vers heißt es: Erweise uns, Herr, deine Huld und gewähre uns dein Heil. Der andere Alleluia-Vers lautet: Aus der Tiefe rufe ich, Herr, zu dir: Herr, höre meine Stimme.

Der Gesang, Offertorium genannt, wurde bei dem Empfang der Gaben der Gläubigen von Priester oder Diakon vorgesehen.

Offertorium A

Perfice gressus meos in semitis tuis, et non moveantur vestigia mea: inclina aurem tuam mihi, et exaudi verba mea: mirifica misericordias tuas, qui salvos facis sperantes in te, Domine [Ps 16, 5. 6b-7]. 
Die Antiphon wurde aus Ps 16 wörtlich entnommen: Führe meine Schritte auf deinen Wegen, damit meine Füße nicht wanken. Wende dein Ohr mir zu, vernimm meine Rede. Wunderbar erweise deine Huld. Du rettest alle, die auf dich hoffen, Herr.

Die Communio begleitete die Prozession der Gläubigen zur Kommunion und wurde immer in den Messformularen vorgeschrieben.

Communio A

$\mathrm{Tu}$ mandasti mandata tua custodire nimis: utinam dirigantur viae meae, ad custodiendas iustificationes tuas [Ps 118, 4-5].

Die Antiphon wurde wörtlich aus Ps 118 übernommen: Du hast deine Befehle gegeben, damit man sie genau beachtet. Wären doch meine Schritte fest darauf gerichtet, deinen Gesetzen zu folgen.

\section{BIBLIOGRAFIA}

Die Heiligen Drei Könige - Darstellung und Verehrung. Katalog zur Ausstellung des WallrafRichartz-Museums in der Josef-Haubrich-Kunsthalle Köln (1. Dez. 1982 bis 30. Jan. 1983), Köln 1982, 16-19.

FlinsPaCh, Karl-Heinz, und Annette Heusch-AltensteIn. Jakobswege. Wege der Jakobspilger im Rheinland, Bd. 1. Köln: J.P. Bachem Verlag, 2001.

FranZ, Adolph. Die Messe im deutschen Mittelalter. Freiburg: Herder, 1902.

SCHAUBER, Vera, und Hanns Michael SCHINDLER (Hgg.). Bildlexikon der Heiligen, Seligen und Namenspatrone. Augsburg: Pattloch, 1999.

Torsy, Jakob. Achthundert Jahre Verehrung der Heiligen Drei Könige in Köln 1164-1964 (= Kölner Domblatt 23/24). Köln: J.P. Bachem Verlag, 1964.

\section{TEKSTY LITURGICZNE KU CZCI ŚWIĘTYCH TRZECH KRÓLI}

$$
\text { Streszczenie }
$$

W niniejszym artykule chodziło o ukazanie czytelnikowi bardzo małego fragmentu z o wiele szerszego zagadnienia: Liturgia dla podróżujących, pielgrzymów i pływających po morzu. Na podstawie badań okazało się, że Kościół, jak wynika z pierwszych spisanych źródeł liturgicznych, tzn. sakramentarzy, a potem zwłaszcza, u szczytu średniowiecza, z pontyfikałów, mszałów i rytuałów troszczył się o tych ludzi poprzez przygotowanie odpowiednich tekstów liturgicznych. Należy wymienić tutaj formularze mszalne: Pro iter agentibus, Pro peregrinantibus i Pro navigantibus. To pierwsza grupa. Drugą grupę stanowią obrzędy błogosławieństwa osób udających się w podróż lub na pielgrzymkę (Ordo ad servicium peregrinorum faciendum) bądź ich utensyliów podróżnych, takich jak torba, laska, krzyż i płaszcz (Benedictio ad baculum et ad peram) oraz obrzędy po powrocie z pielgrzymki czy podróży (Benedictio peregrinorum post reditum). Z tego bogactwa modlitw niewiele formuł w liturgii posoborowej pozostało w użyciu. 
Osobny i bardzo interesujący rozdział stanowią teksty liturgiczne, które są związane z patronatem niektórych świętych, takich jak św. Jakub Starszy, św. Rafał Archanioł, św. Julian i św. Krzysztof oraz Święci Trzej Królowie. W przypadku Świętych Trzech Króli, którzy uważani byli w średniowieczu za patronów podróżujących i pielgrzymów i których relikwie w katedrze kolońskiej ściągały zarówno nowo koronowanych królów, jak i rzesze innych pielgrzymów z całej Europy, chodzi o pierwszych pielgrzymów epoki chrześcijańskiej, którzy odbyli pielgrzymkę do nowo narodzonego Jezusa Chrystusa. Zastanawiające jest to, że formularze mszalne (bo obrzędy błogosławieństwa nie są znane), można sklasyfikować w cztery grupy. W całej Europie - od Anglii po Niemcy i Polskę - można je znaleźć w wielu mszałach średniowiecznych, ale nie w mszałach kolońskich.

W niniejszym artykule przedstawiono tylko pierwszy formularz mszalny De tribus magis pro iter agentibus. Oracje mszalne rozwijają motyw drogi magów ze Wschodu do Betlejem, aby pokłonić się Mesjaszowi, którego szczególna gwiazda wzeszła na niebie i ich do Niego zaprowadziła, aby mogli Go uczcić mistycznymi darami. Kościół modli się za swoich wiernych zdążających w pielgrzymce, aby za przyczyną tych świętych i przez ich zasługi przebiegała ona w pokoju, zdrowiu i pomyślności. Sam Chrystus, nazwany prawdziwym Słońcem, Gwiazdą i Światłością, niech ich prowadzi bez szwanku do upragnionego sanktuarium. Dalej Kościół prosi Boga, aby dał pielgrzymom Anioła pokoju jako towarzysza drogi, strzegącego ich przed niebezpieczeństwami ciała i duszy oraz przed atakami starego wroga, tzn. szatana, a także by stali się godni towarzystwa Ducha Świętego. Kolejna myśl poruszona w euchologii to dzieje Syna Bożego (wcielenie, męka i zmartwychwstanie) oraz rola aniołów jako Jego świadków, która ma się przedłużyć w opiece dniem i nocą nad pielgrzymami. W pierwszym czytaniu biblijnym (Rdz 24, 7) chodzi o podróż Abrahama do jego ojczyzny i obietnicę anioła jako towarzysza drogi. Natomiast perykopa ewangelijna ( $Ł k$ 4, 23b-30) to rozmowa faryzeuszów z Jezusem, który w swojej ojczyźnie nie jest przyjmowany $\mathrm{z}$ otwartymi rękami. W czasie tej rozmowy ważną rolę odgrywa napięcie między obczyzną i ojczyzną oraz obcym i swoim. Z tego względu pewnie nastąpił wybór tej perykopy do formularza mszalnego. Antyfony mszalne (introitus, graduale, offertorium i communio) mają jako źródło fragmenty psalmów i podejmują typowe dla omawianego tematu motywy: prowadzenie przez Boga w drodze, towarzystwo aniołów w drodze, zaufanie Bogu oraz ratunek w Bogu. Sekwencja Maiestati sacrosantae militans, która była czasami dołączana do tego formularza, będzie omówiona w osobnym artykule.

Słowa kluczowe: podróż; pielgrzymka; modlitwa za pielgrzymujących i podróżujących; opieka Boża; święci patronowie; św. Trzej Królowie; aniołowie. 